NASA/TM-2002-211818

\title{
Flutter Analysis of a Transonic Fan
}

R. Srivastava, M.A. Bakhle, and T.G. Keith, Jr.

University of Toledo, Toledo, Ohio

G.L. Stefko

Glenn Research Center, Cleveland, Ohio 
Since its founding, NASA has been dedicated to the advancement of aeronautics and space science. The NASA Scientific and Technical Information (STI) Program Office plays a key part in helping NASA maintain this important role.

The NASA STI Program Office is operated by Langley Research Center, the Lead Center for NASA's scientific and technical information. The NASA STI Program Office provides access to the NASA STI Database, the largest collection of aeronautical and space science STI in the world. The Program Office is also NASA's institutional mechanism for disseminating the results of its research and development activities. These results are published by NASA in the NASA STI Report Series, which includes the following report types:

- TECHNICAL PUBLICATION. Reports of completed research or a major significant phase of research that present the results of NASA programs and include extensive data or theoretical analysis. Includes compilations of significant scientific and technical data and information deemed to be of continuing reference value. NASA's counterpart of peerreviewed formal professional papers but has less stringent limitations on manuscript length and extent of graphic presentations.

- TECHNICAL MEMORANDUM. Scientific and technical findings that are preliminary or of specialized interest, e.g., quick release reports, working papers, and bibliographies that contain minimal annotation. Does not contain extensive analysis.

- CONTRACTOR REPORT. Scientific and technical findings by NASA-sponsored contractors and grantees.
- CONFERENCE PUBLICATION. Collected papers from scientific and technical conferences, symposia, seminars, or other meetings sponsored or cosponsored by NASA.

- SPECIAL PUbLiCATION. Scientific, technical, or historical information from NASA programs, projects, and missions, often concerned with subjects having substantial public interest.

- TECHNICAL TRANSLATION. Englishlanguage translations of foreign scientific and technical material pertinent to NASA's mission.

Specialized services that complement the STI Program Office's diverse offerings include creating custom thesauri, building customized databases, organizing and publishing research results ... even providing videos.

For more information about the NASA STI Program Office, see the following:

- Access the NASA STI Program Home Page at http://www.sti.nasa.gov

- E-mail your question via the Internet to help@sti.nasa.gov

- Fax your question to the NASA Access Help Desk at 301-621-0134

- Telephone the NASA Access Help Desk at 301-621-0390

- Write to:

NASA Access Help Desk

NASA Center for AeroSpace Information 7121 Standard Drive Hanover, MD 21076 
NASA/TM-2002-211818

\section{Flutter Analysis of a Transonic Fan}

R. Srivastava, M.A. Bakhle, and T.G. Keith, Jr.

University of Toledo, Toledo, Ohio

G.L. Stefko

Glenn Research Center, Cleveland, Ohio

National Aeronautics and

Space Administration

Glenn Research Center

September 2002 


\section{Acknowledgments}

This work was performed under funding from the Quiet Aircraft Technology Project of NASA Glenn Research Center. Joseph E. Grady is the project manager. The authors also wish to gratefully acknowledge the assistance and suggestions provided by Joseph Panovsky of Honeywell Engines, Systems, \& Services, Brian Fite of NASA Glenn and John A. Gazzaniga of QSS Group, Inc.

Available from

NASA Center for Aerospace Information 7121 Standard Drive

Hanover, MD 21076
National Technical Information Service 5285 Port Royal Road Springfield, VA 22100 


\title{
FLUTTER ANALYSIS OF A TRANSONIC FAN
}

\author{
R. Srivastava, ${ }^{*}$ M.A. Bakhle, ${ }^{*}$ and T.G. Keith, Jr. \\ University of Toledo \\ Toledo, Ohio 43606
}

\author{
G.L. Stefko \\ National Aeronautics and Space Administration \\ Glenn Research Center \\ Cleveland, Ohio 44135
}

\begin{abstract}
This paper describes the calculation of flutter stability characteristics for a transonic forward swept fan configuration using a viscous aeroelastic analysis program. Unsteady NavierStokes equations are solved on a dynamically deforming, body fitted, grid to obtain the aeroelastic characteristics using the energy exchange method. The non-zero inter-blade phase angle is modeled using phase-lagged boundary conditions. Results obtained show good correlation with measurements. It is found that the location of shock and variation of shock strength strongly influenced stability. Also, outboard stations primarily contributed to stability characteristics. Results demonstrate that changes in blade shape impact the calculated aerodynamic damping, indicating importance of using accurate blade operating shape under centrifugal and steady aerodynamic loading for flutter prediction. It was found that the calculated aerodynamic damping was relatively insensitive to variation in natural frequency.
\end{abstract}

\section{INTRODUCTION}

Reducing noise has become a significant criterion in the design of modern turbomachinery fans. For fans with supersonic tip speeds, shock waves play a significant role in the generation of noise. Aggressive blade designs with forward sweep and lean are being used to improve the noise characteristics. These geometric features coupled with the presence of shock wave can lead to flutter instability. Flutter problems, usually detected during the design phase, result in program delays and cost overruns, adversely impacting the development and maintenance costs. Numerical flutter prediction methods will help in achieving the design objectives and developing a flutter free design.

Several methods have been developed for the prediction of aeroelastic characteristics of turbomachines with various degrees of fidelity. Aeroelastic analyses based on energy exchange between vibrating blades and the surrounding fluid, have been reported for turbomachines using semi-analytical methods (Lane and Friedman [1], Smith [2]), linearized methods (Hall and Clark [3], Verdon [4]), Euler methods (He [5], Gerolymos and Vallet [6], Bakhle, et al. [7]) and viscous methods (Giles and Haimes [8], Siden [9], He and Denton [10]). A limited number of coupled aeroelastic analyses of turbomachine configurations have also been reported [11-13]. Williams, Cho, and Dalton [11] used a linear panel method to solve the eigenvalue problem. Gerolymos [12] and Srivastava and Reddy [13] solved the coupled aeroelastic equations based on an inviscid aerodynamic analysis. The majority of the methods are either analytical, applicable to two-dimensional geometry and/or ignore the viscous effects.

The modern fans being designed to reduce noise are swept forward as well as leaned in the plane of rotation. These features coupled with transonic flow result in aeroelastic problems. For turbomachinery blade rows, flutter is observed primarily in single natural mode. Single mode flutter can be captured using the energy exchange method, which calculates the flow of energy between the vibrating blade and the surrounding fluid. A three-dimensional viscous aeroelastic analysis code TURBO-AE, based on energy exchange method has been developed and reported in [14]. The objective of the present study is to investigate the stability of a forward swept transonic fan geometry. The transonic fan analyzed, showed flutter at part speed. The TURBO-AE code is applied to calculate the flutter observed in the wind tunnel and to understand the flow features that caused the instability.

Modern fan blades, by virtue of having a small thickness ratio coupled with forward sweep could be highly flexible in the tip region. High rotational speed and large aerodynamic loading result in significant changes in blade shape. It is important to accurately account for these changes in the analysis. To investigate the sensitivity of damping calculations to changes in steady blade deflection, calculations are also carried out by deforming the blade at the tip to change the blade twist by 0.5 deg such that the incidence angle at the section is increased. Also, results are obtained to investigate the impact of time step used in the analysis and sensitivity to natural frequency variation. These studies are carried out to gain an understanding of issues that need to be addressed in flutter analyses of similar fan configurations.

\section{THE TURBO-AE CODE}

The aeroelastic solver TURBO-AE is briefly described in this section. The solver can model multiple blade rows undergoing harmonic oscillations with arbitrary inter-blade phase angles (IBPAs). It is based on a Navier-Stokes unsteady aerodynamic solver for internal flow calculations of axial flow

*NASA Resident Research Associate at Glenn Research Center. 
turbomachinery components, TURBO $[15,16]$. Viscous effects are modeled using the Reynolds-averaged Navier-Stokes equations. The two-equation $\mathrm{k}-\varepsilon$ turbulence model is used for closure. The aerodynamic equations are solved using a finite volume scheme. Flux vector splitting is used to evaluate the flux Jacobians on the left-hand side. The right-hand side fluxes are discretized using the high order Total Variation Diminishing (TVD) scheme based on Roe's flux difference splitting. Newton subiterations are used at each time-step to maintain accuracy. Symmetric Gauss-Seidel iterations are applied to the discretized equations for improved convergence.

The aeroelastic characteristics of the rotor are obtained by calculating the energy exchange between the vibrating blade and its surrounding fluid. Positive work on blade indicates instability. The aeroelastic analysis is performed by first obtaining the "steady" aerodynamic solution for a given operating condition. The blades are then forced into a prescribed harmonic motion (specified mode, frequency, and IBPA) to calculate the unsteady aerodynamic response and thereby work-per-cycle W, Eq. 1 .

$$
W=\oint \int_{\text {surface }}-p \cdot d \vec{A} \cdot\left(\frac{\partial \vec{X}}{\partial t}\right) d t
$$

Where, $p$ is the surface pressure, $\overrightarrow{\boldsymbol{A}}$ is the area of the blade surface and $\overrightarrow{\boldsymbol{X}}$ is the blade displacement associated with the forced harmonic vibration. The work $\mathrm{W}$ is then used to calculate the aerodynamic damping $\gamma$, using the average kinetic energy $K_{E}$ of the blade over one vibration cycle [17], Eq. 2.

$$
\gamma=-\frac{W}{8 \pi K_{E}}
$$

The blade motion is simulated using a dynamic grid deformation technique. Phase-lagged boundary conditions are used to calculate the non-zero IBPA vibrations, which eliminates the need to model multiple blade passages.

\section{RESULTS AND DISCUSSION}

A scale model of an experimental transonic fan with 22 blades (Fig. 1) was tested in a rig. The design operating condition for the model tested was mass flow of $98.89 \mathrm{lbs} / \mathrm{s}$ with a relative tip Mach number of 1.4. The fan fluttered at part speed in the first natural mode [18], between the operating line and predicted stall line. The first natural mode is shown in Fig. 2, hotter colors signifying larger displacements. The mode shows a high degree of twist bend coupling, especially in the outboard section..

The results are presented here for 90 percent rotational speed. A grid with approximately 213,000 grid points per blade passage, 46 axial by 47 radial points on each surface, and a uniform tip-gap is used in the analysis. The blade shape and modal properties for 100 percent speed are used.

Figure 3 shows the steady aerodynamic loading on the blade surfaces for 90 percent speed at a condition near the operating line. Shock wave structures are clearly evident from these figures. An oblique shock appears near the leading edge on the suction surface over the entire span. A normal shock extends across the blade passage in the aft section of the blade

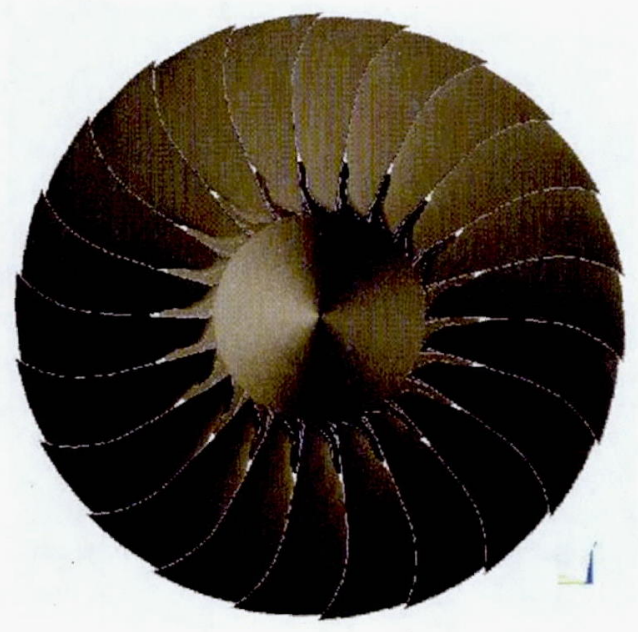

Figure 1. Transonic fan

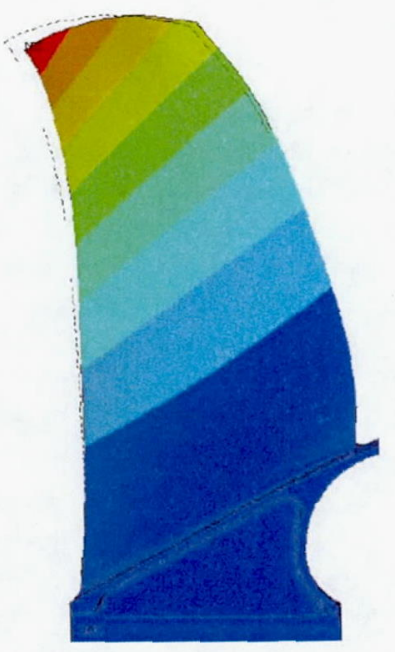

Figure 2. First natural mode

on the suction surface. For the in-board sections, this shock is outside the blade passage (in front of blade leading edge) on the pressure surface side. However, the shock is completely ingested within the passage in the outboard sections of the blade. This shock pattern is typical for a flow condition referred to as moderate to high loading for blades with a supersonic leading edge operating in subsonic axial flow. As the back pressure is increased, moving the operation point towards the stall line, the shock moves forward and becomes stronger. This results in flow separation on the suction surface in the middle section of the blade. The separation is large enough to stall the blade resulting in a break down of the numerical analysis. The observed breakdown of the analysis due to flow separation could not be verified, as velocity profiles were not measured during the experiment. 


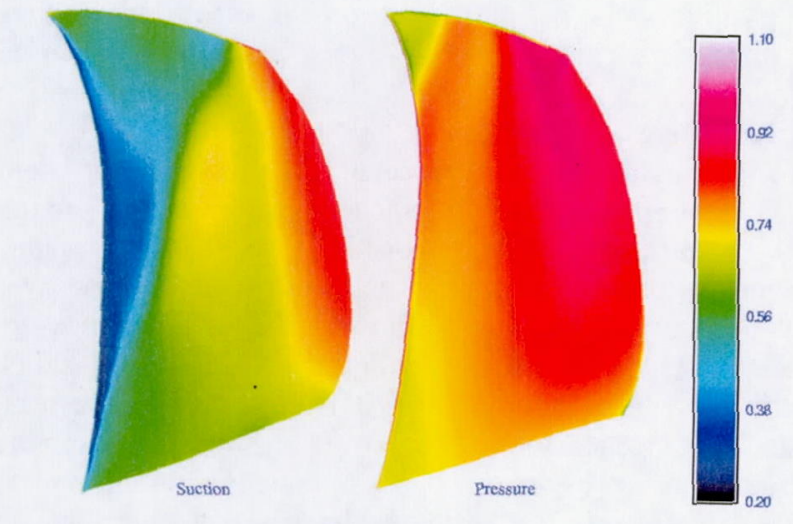

Figure 3. Steady blade surface pressure near operating line for 90 percent speed

\section{Dynamic Analysis}

Experiments showed blade flutter in the first natural mode, Fig. 2, (natural frequency $351 \mathrm{~Hz}$ ) for $32.73 \mathrm{deg}$ IBPA (2 Nodal Diameter forward traveling wave) [18]. To establish the least stable mode the analysis was carried out for several pressure ratios and IBPAs.

Flow separation for higher back pressures was observed in the hub region of the blade resulting in unsteadiness of the mean flow. Because of the mean flow unsteadiness, one needs to ensure that the blade vibration amplitude is large enough so as to minimize the impact of mean flow unsteadiness on the unsteadiness due to blade vibrations, yet should be small enough to maintain linearity. The calculated time history of mass flow is shown in Fig. 4 for flow with and without blade vibration for a back pressure of 16.2 pounds per square inch (psi). The blade is forced into vibration at $180 \mathrm{deg}$ IBPA and $351 \mathrm{~Hz}$. It can be seen from Fig. 4 that for the vibration amplitude chosen for the analysis, the unsteadiness due to blade vibration is at least an order of magnitude larger than the mean flow unsteadiness. It can also be seen that the flow converges to periodicity in roughly 10 oscillations.

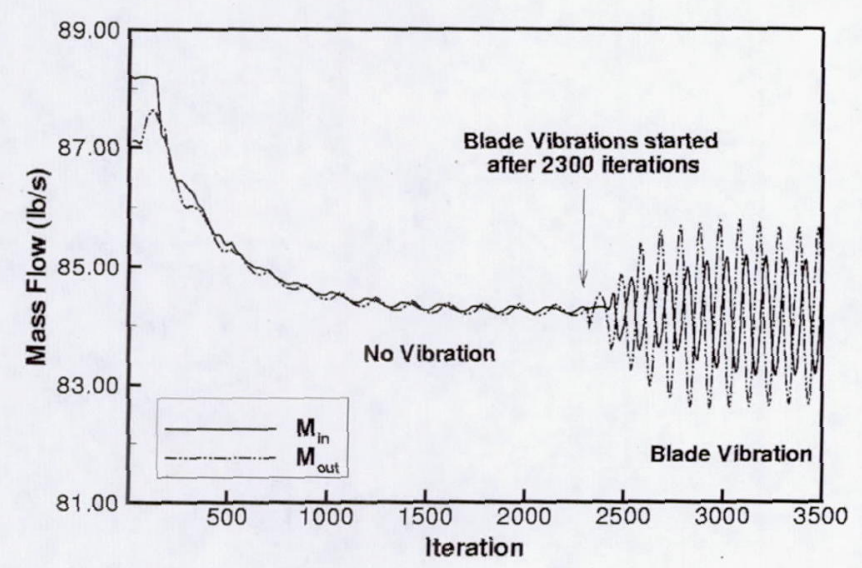

Figure 4. Variation of mass flow for the transonic fan, with and without blade vibration
Figure 5 shows the aerodynamic damping calculated for several different back pressures and IBPAs. For lower back pressures, the least stable IBPA was found to be 0 deg. However, as the back pressure was raised moving the fan operating condition towards the stall line, the 32.73 deg IBPA ( 2 nodal diameter forward traveling wave) became the least stable. Flutter was observed in the wind tunnel for $32.73 \mathrm{deg}$ IBPA.

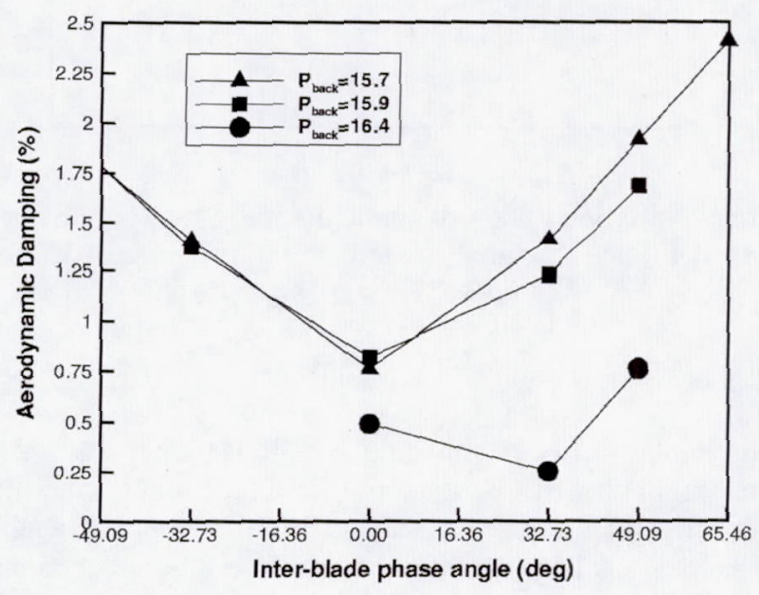

Figure 5. Variation of aerodynamic damping with back pressure and IBPA for the transonic fan

The calculated variation of aerodynamic damping with back pressure is shown in Fig. 6 at $32.73 \mathrm{deg}$ IBPA. As may be seen in the figure, as the back pressure is increased, the aerodynamic damping decreases rapidly, dropping to approximately 0.2 percent of critical damping at a back pressure of 16.4 psi. Increasing the back pressure above 16.4 psi for 90 percent speed resulted in stalled flow with large separation on the suction surface in the mid section of the blade. This separation was found to be shock induced and prevented a steady mean flow from which the blade vibration analysis could be carried out. These results indicate that the $32.73 \mathrm{deg}$ IBPA is the least stable IBPA for first natural mode, as observed in experiments, and that the aerodynamic damping rapidly decreases with increasing back pressure.

From Fig. 6 it is evident that the characteristics of variation of aerodynamic damping changes significantly as the back pressure is varied. Initially the damping is not affected much by an increase in back pressure, at least up to the operating line, which falls close to a back pressure of 15.7 psi. Further increase of the back pressure results in a dramatic change in damping variation, becoming inversely proportional to variation in back pressure. To understand the reason for such a change, flow details were investigated for back pressure values of $15.2,15.9$ and 16.4 psi. Figure 7 shows the distribution of work on the blade surface. Majority of the blade shows little 


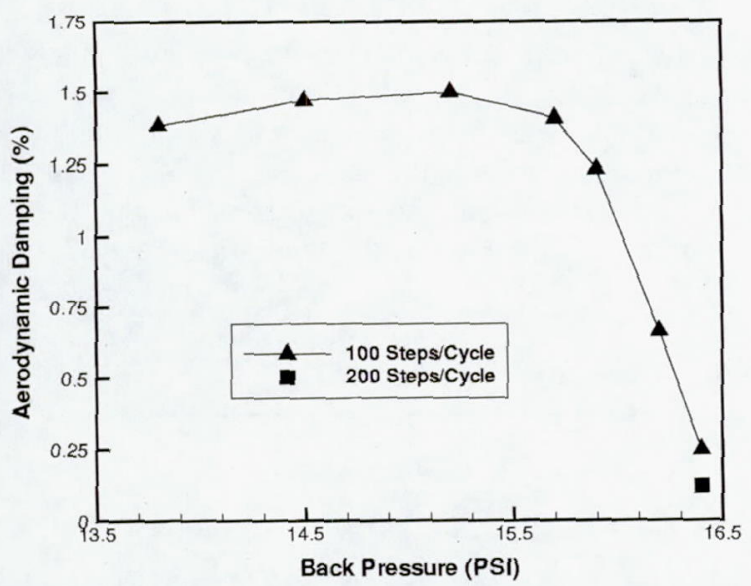

Figure 6. Variation of aerodynamic damping for 16.4 PSI back pressure. Forced vibration in the first natural mode at $351 \mathrm{~Hz}$ and 32 deg IBPA

contribution towards establishing the flutter characteristics of the blade. Outboard sections of the blade contribute most significantly. This has a side benefit from an analysis perspective. Resolving the flowfield on the inboard sections is probably not significant and hence coarse grid may be used in this region, concentrating more grids in the outboard sections of the blade. These figures also show that over certain areas on the
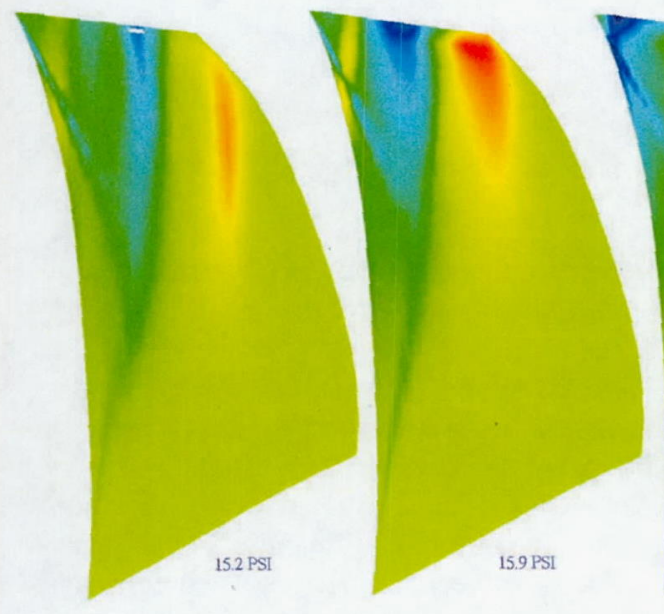

\section{Work}

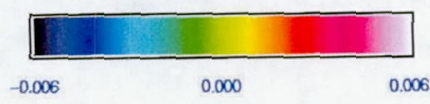

Figure 7. Work distribution on blade surface for various back pressures blade positive work is being done on the blade indicating a destabilizing contribution. These plots, when superimposed with relative Mach number plots, indicate that the positive work regions are centered around the shock location.

To investigate this in more detail, the pressure coefficient at 90 percent span, around the shock location on the suction surface, is plotted in Fig. 8 for the three back pressures. Instantaneous pressure coefficient at five instants of time over one period of oscillation is shown. The steady pressure coefficient is also shown to highlight the variation of shock strength from the mean position. It is clear that as the back pressure is increased the shock moves upstream. Also, the variation in the pressure change associated with the shock, changes significantly. It is these changes that contribute to positive work on the blade. These figures indicate that the location of shock and associated changes in strength are responsible for the change in characteristics of the variation of damping and are responsible for flutter.

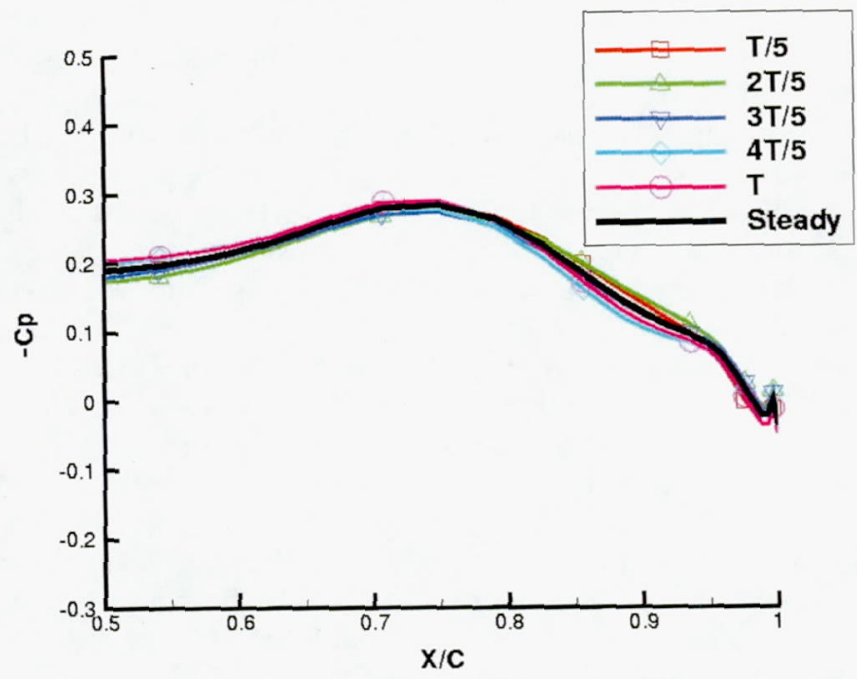

(a) back pressure $15.2 \mathrm{psi}$

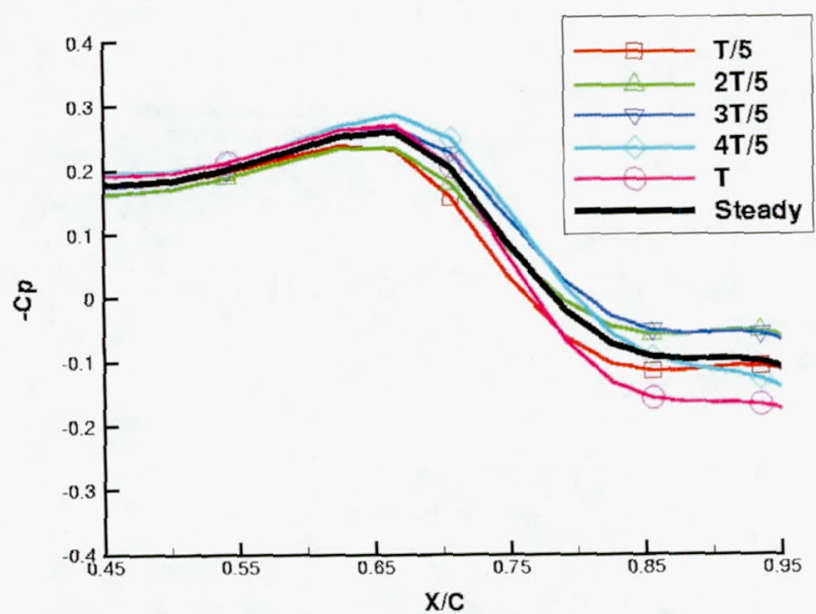

(b) back pressure 15.9 psi 


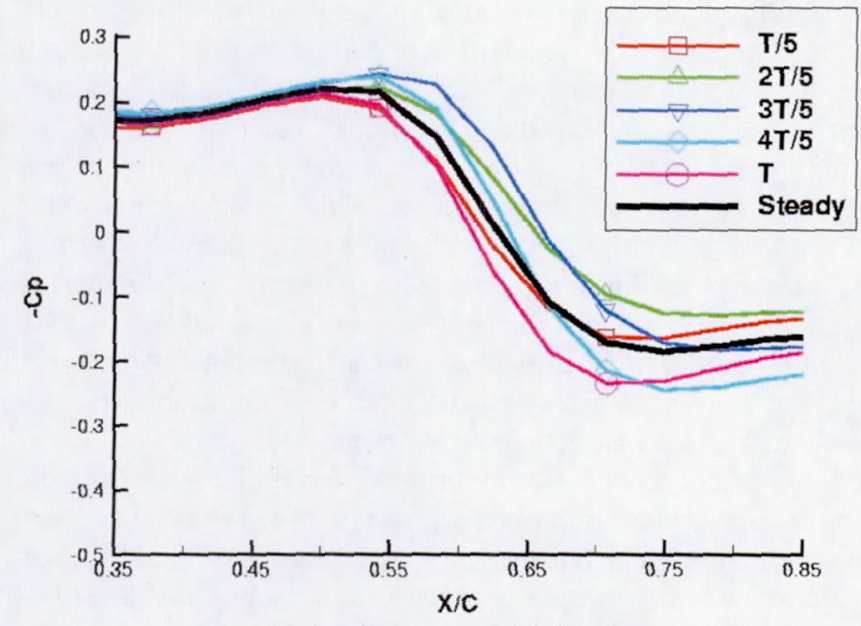

(c) back pressure 16.4 psi

Figure 8. Pressure coefficient variation over one period of oscillation cycle for back pressures of $15.2,15.9,16.4 \mathrm{psi}$

The blade natural vibration frequency for a rotor is proportional to the rotational speed. Hence, for 90 percent speed the blade natural frequency would be lower than that at 100 percent speed. To investigate the impact of change in frequency, a sensitivity study was carried out by varying the natural frequency. Calculations were performed for 20 percent higher as well as 20 percent lower natural frequency for 100 percent speed at $32.73 \mathrm{deg}$ IBPA. These changes in frequency resulted in changes of less than 0.1 percent of critical damping ratio, indicating a low sensitivity to natural frequency. It should be noted here that changes in rotational speed will also impact the mode shape, however, in the present study no attempt was made to alter the mode shape.

Analysis was also performed at the second natural vibration mode, which was stable in the experiment. The aerodynamic damping calculated was much higher than those for the first mode, indicating the second mode to be more stable than the first mode. These results show that the analysis successfully calculates the natural mode and IBPA of instability identifying the flutter characteristics of the transonic fan.

For the back pressure of $16.4 \mathrm{psi}$, the experiment showed flutter, whereas the analysis predicted the fan to be marginally stable. The analysis correctly predicted the least stable mode, however, it did not predict a negative aerodynamic damping. A possible reason for that was thought to be the use of an inaccurate operating blade shape. The analysis at the 90 percent speed was performed using the design speed geometry and characteristics. To investigate the influence of changes in blade shape on the aerodynamic damping, the analysis was carried out by altering the twist distribution, such that the blade twist changed from mid-span to tip varying linearly from zero change at mid span to $0.5 \mathrm{deg}$ change at the tip. The change in twist distribution is such that it increases the incidence of the blade. Structural analysis showed the blade twist change at the tip to be of this order for the 90 percent speed. The variation in aerodynamic damping with oscillation cycles is shown in Fig. 9. The changes in twist reduce the damping moving it closer to instability. Earlier studies have shown smaller time steps to have moderate impact on the damping calculation, see Fig. 6. As the calculated damping is close to zero, the impact of smaller time steps was also investigated. Most of the analysis was carried out using 100 steps per oscillation cycle in order to minimize the computational cost. The computational cost varies linearly with the number of steps per cycle used in the analysis. Three different time steps were used, 100, 200 and 300 steps per oscillation cycle. The impact of time step size is also shown in Fig. 9. From 100 steps per cycle to 200 steps per cycle there is a measurable change in damping. Whereas using 300 steps per cycle the change is small and does not justify the additional computational cost. From this study it was decided that the 100 steps per cycle is good for investigating the trends of the behavior. For cases where a more accurate damping value is required, 200 steps per cycle should be used. Since the difference is approximately 0.2 percent of critical damping, use of smaller time steps will be significant only in the neighborhood of zero damping or flutter boundary.

Figure 10 compares the steady pressure coefficient and work contributions from the suction and pressure surfaces at the 95 percent span location. The results for the original grid are (Fig. 10(a)) obtained using 100 steps per cycle, where as for the deformed grid the results (Fig. 10(b)) are for 200 steps per cycle. These comparisons are to understand the differences in calculated damping for the deformed shape. Primarily the

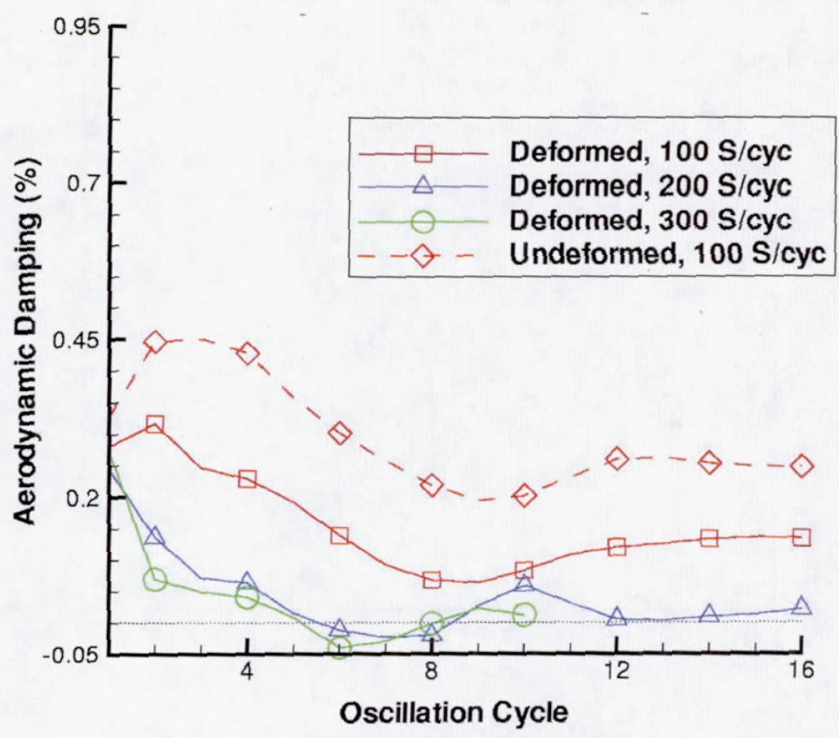

Figure 9. Effect of time steps and change in twist distribution for a 0.5 deg change in twist at tip of the blade 
suction surface contributes to the positive work whereas the pressure surface contributes to negative work providing a stabilizing influence. The area of positive work is centered around the normal shock on the suction surface. However, there are two main differences that are observed from these figures. First, we find that the shock on the suction surface has moved upstream by roughly 5 percent. In addition, the work

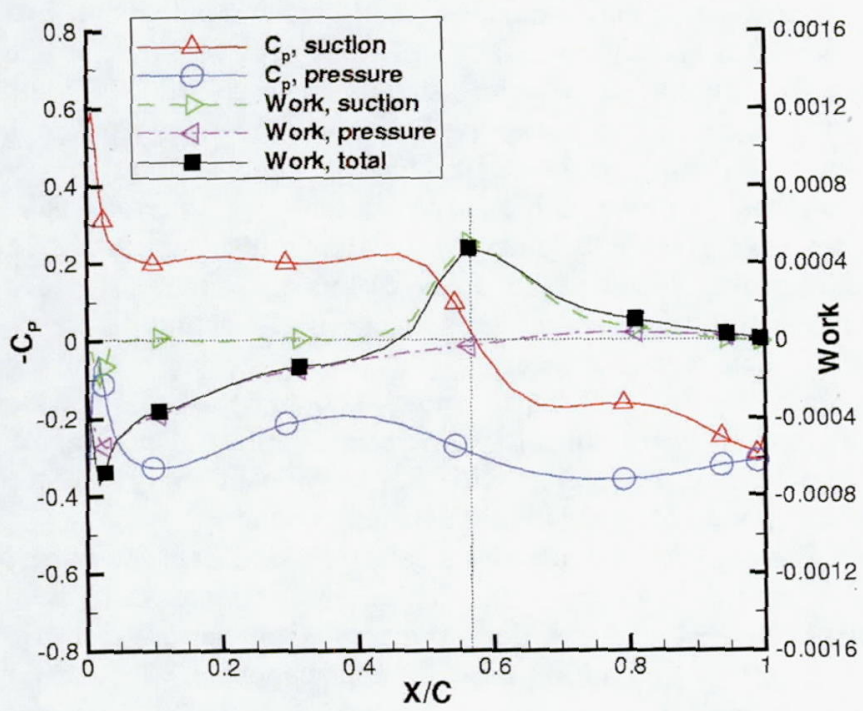

(a) Original Geometry

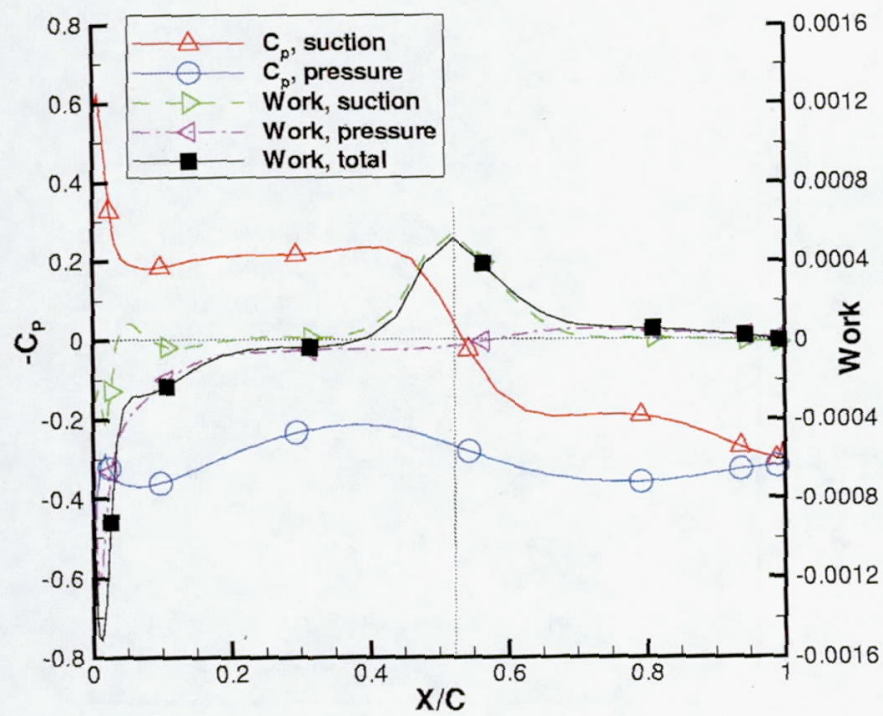

(b) Deformed geometry

Figure 10. Pressure coefficient and work distribution at 95 percent span contribution associated with this shock has also moved. Only minor changes in the level of work are observed. A second change, which is more significant from the work perspective, is seen on the pressure surface. The area of negative work in the leading edge region is reduced, and the peak is higher but narrower for the deformed shape. This change contributes mainly to a reduction in the damping for the deformed shape. The primary reason for this difference is the motion of the shock on the pressure surface. Figure 11 shows the steady pressure contours and Fig. 12 show the instantaneous pressure contours at five instants of time over the vibration cycle for steady and deformed geometry at 95 percent span. The steady contours show that a normal shock wave extends from the suction surface across the blade passage. For the original grid, the shock intersects the pressure surface at the leading edge, whereas for the deformed geometry the shock is just ahead of the leading edge. Figure 12 shows the shock movement over the oscillation cycle for the two geometries considered here. Instantaneous pressure contours near the pressure surface leading edge are shown for five time instants over one cycle of vibration. For ease of comparison, these contours are plotted next to each other going from left to right with increasing time. The pressure surface, leading edge, and time instants corresponding to the contour are marked on the figures. From Fig. 12 a it can be seen that the shock stays on the blade surface for the original geometry, whereas for the deformed geometry (Fig. $12 \mathrm{~b}$ ), the shock intersects the blade for part of the vibration cycle, moving on and off the blade surface over the oscillation cycle. This shock motion on and off the blade

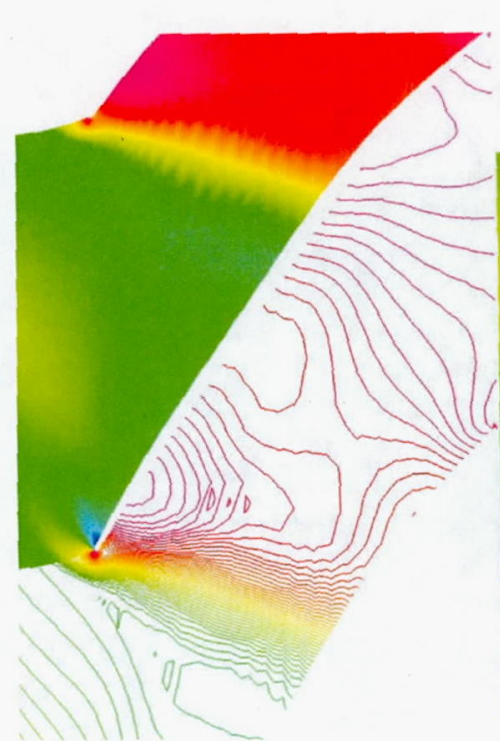

Original geometry

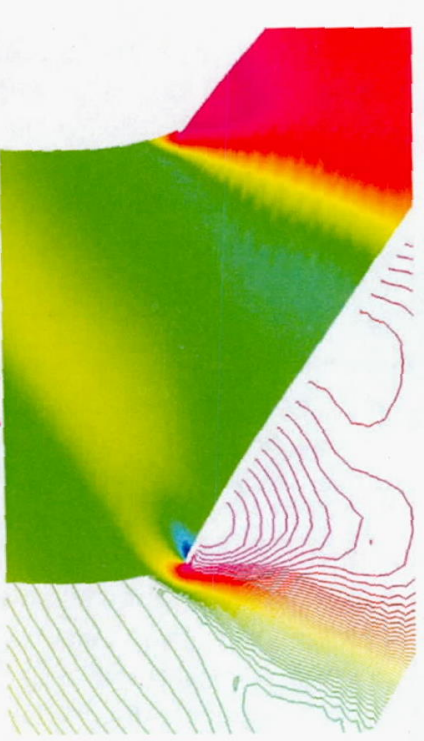

Deformed geometry
Figure 11. Pressure contours for 16.4 psi at 95 percent span 
surface is the reason for differences in work contribution on the pressure surface between the two geometries. The effect of this motion is to reduce the overall stabilizing effect from the pressure surface, reducing the aerodynamic damping for the deformed geometry.

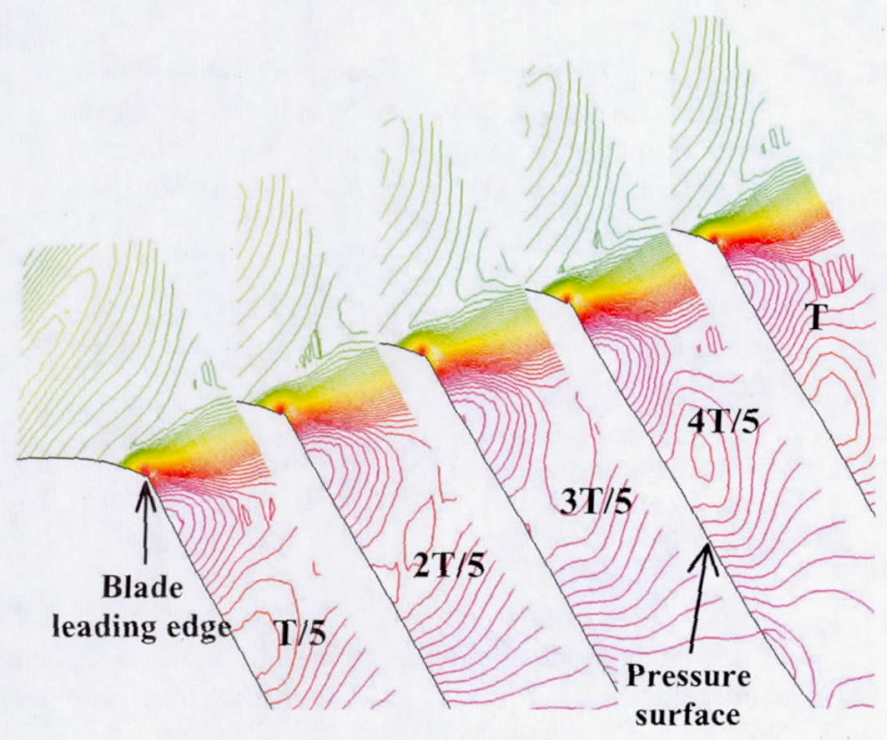

(a) Original geometry

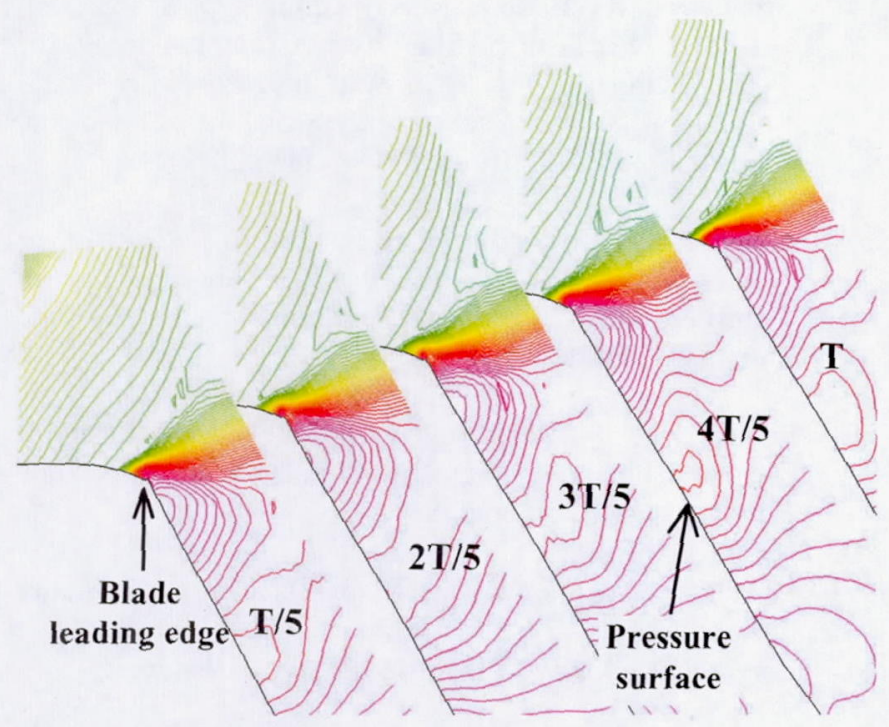

(b) Deformed geometry

Figure 12. Instantaneous pressure contours over one vibration cycle with time period $T$, near pressure surface leading edge at 95 percent span for back pressure of 16.4 psi

Approximately 95 Mega Words of computer memory and one hour of computational time per 100 steps was required on the Cray C-90 computer located at the NAS facility of NASA.

\section{CONCLUDING REMARKS}

An aeroelastic analysis program based on the NavierStokes equation has been used to calculate the flutter characteristics and to investigate the behavior of aerodynamic damping variation for a forward swept transonic fan geometry. Calculated variations of aerodynamic damping with back pressure and IBPA is presented for a condition where flutter occurred during testing. Although a negative aerodynamic damping was not calculated, the analysis yielded some good results and trends. The analysis correctly predicted the mode and IBPA of flutter. Also, the trend for calculated aerodynamic damping clearly indicated a negative aerodynamic damping would result with further increasing the back pressure. Unfortunately, the analysis showed that a stalled flow field would emerge for any further increase of the back pressure. Although flow separation was captured along with vortex shedding, deep blade stall posed a numerical problem. Results also showed that a majority of the blade surface does not contribute towards the stability characteristics. But the stabilizing and destabilizing effects were concentrated near the shock location and were restricted to outboard stations of the blade.

Detailed examination of the flow features indicated that normal shock on suction surface has a destabilizing effect and results in a large area of positive work centered around the normal shock. The area of the destabilizing effects depended on the location of the shock. Higher back pressure moved the normal shock forward increasing the area of positive work. This coupled with the mode shape resulted in an increased variation of the blade surface pressure over one oscillation cycle causing the destabilizing influence to increase.

A study was also performed to understand the effect of various parameters on the calculation of aerodynamic damping. The study showed that the aerodynamic damping was insensitive to the variations in vibration frequency. However, it should be noted that only the frequency was altered without altering the mode shape. It was also found that the blade shape under operating conditions is important. A small change of 0.5 deg in twist at the blade tip led to a better correlation of damping with measurements, where the original shape had predicted marginal positive damping. Changes in blade shape, although moved the suction surface shock further upstream in the outboard sections, do not measurably change the level of positive work. On the other hand, the negative work on pressure surface was reduced in the front section of the blade reducing the overall blade stability, resulting in better correlation with measurements. Thus it is important to use the correct shape in the analysis for more accurate calculation of damping, especially near the flutter boundary.

Changes in time step for unsteady analysis were found to have a moderate impact. Although the trends did not change, the smaller time step reduced the aerodynamic damping. However, these differences would be of significance for damping calculations only in the vicinity of neutral stability. 
From these studies the following conclusions can be drawn that could be useful in similar analyses:

(a) Shock location and its strength have a strong influence on blade stability

(b) In-board sections of the blade do not contribute towards establishing the stability characteristics, thus a coarser grid in this region can be used to reduce computational cost.

(c) Accurate blade operating shape is important for accurate damping prediction as it establishes the shock structure on the blade, which in turn affects the stability. Variations in vibration frequency were found to be less significant.

(d) Larger time steps can be used away from the neutral stability region for determining the trends, however, close to neutral stability; smaller time steps need to be used for accurate stability predictions.

\section{REFERENCES}

[1] Lane, F. and Friedman, M., "Theoretical Investigation of Subsonic Oscillating Blade-row Aerodynamics," NACA TN 4136, 1958.

[2] Smith, S.N., "Discrete Frequency Sound Generation in Axial Flow Turbomachines," R\&M 3709, British Aeronautical Research Council, London, England, UK, 1972.

[3] Hall, K.C., Clark, W.S., "Linearized Euler Predictions of Unsteady Aerodynamic Loads in Cascades," AIAA Journal, Vol. 31, pp.540-550, 1993.

[4] Verdon, J.M., "Unsteady Aerodynamic Methods for Turbomachinery Aeroelastic and Aeroacoustic Applications," AIAA Journal, Vol. 31, No. 2, pp. 235$250,1993$.

[5] He, L., "An Euler Solution for Unsteady Flows Around Oscillating Blades," ASME Journal of Turbomachinery, Vol. 112, No. 4, pp. 714-722, 1989.

[6] Gerolymos, G.A., and Vallet, I., "Validation of 3-D Euler Methods for Vibrating Cascade Aerodynamics," ASME Paper 94-GT-294, 1994.

[7] Bakhle, M. A., Srivastava, R., Keith, T. G. Jr., Stefko, G. L., "A 3D Euler/Navier-Stokes Aeroelastic Code for Propulsion Applications,” AIAA Paper 97-2749, 1997.
[8] Giles, M., Haimes, R., "Validation of a Numerical Method for Unsteady Flow Calculations," ASME Paper 91-GT-271, 1991.

[9] Siden, L.D.G., "Numerical Simulation of Unsteady Viscous Compressible Flows Applied to a Blade Flutter Analysis," ASME Paper No. 91-GT-203, 1991.

[10] He, L. and Denton, J.D., "Three Dimensional Time Marching Inviscid and Viscous Solutions for Unsteady Flows Around Vibrating Blades," ASME Journal of Turbomachinery, Vol. 116, pp. 469-476, 1994.

[11] Williams, M.H., Cho, J., Dalton, W.N., "Unsteady Aerodynamic Analysis of Ducted Fans," Journal of Propulsion and Power, Vol. 7, No. 5, pp. 800-804, 1991.

[12] Gerolymos, G.A, "Coupled 3-D Aeroelastic Stability Analysis of Bladed Disks," ASME Paper no. 92-GT$171,1992$.

[13] Srivastava, R., and Reddy, T.S.R., "Comparative Study of Coupled-Mode Flutter-Analysis Methods for Fan Configurations," Journal of Propulsion and Power, Vol. 15, No. 3, pp. 447-453, 1999.

[14] Srivastava, R., Bakhle, M.A., Keith, T.G. Jr., Stefko, G.L. "Aeroelastic Stability Computations for Turbomachinery," Proceedings of the 2001 International Forum on Aeroelasticity and Structural Dynamics, Madrid, Spain, Vol. III pp. 77-86, June 2001.

[15] Chen, J.P., "Unsteady Three-Dimensional Thin-Layer Navier-Stokes Solutions for Turbomachinery in Transonic Flow," Ph. D. Dissertation, Mississippi State University, 1991.

[16] Janus, J.M., "Advanced 3-D CFD Algorithm for Turbomachinery," Ph. D. Dissertation, Mississippi State University, Mississippi, 1989.

[17] Carta, F.O., "Coupled Blade-Disk-Shroud Flutter Instabilities in Turbojet Engine Rotors," Journal of Engineering for Power, July 1967, pp. 419-426.

[18] Fite, B.E., Private Communications, NASA Glenn Research Center, January, 2001. 
Public reporting burden for this collection of information is estimated to average 1 hour per response, including the time for reviewing instructions, searching existing data sources, gathering and maintaining the data needed, and completing and reviewing the collection of information. Send comments regarding this burden estimate or any other aspect of this collection of information, including suggestions for reducing this burden, to Washington Headquarters Services, Directorate for Information Operations and Reports, 1215 Jefferson Davis Highway, Suite 1204, Arlington, VA 22202-4302, and to the Office of Management and Budget, Paperwork Reduction Project (0704-0188), Washington, DC 20503.

\begin{tabular}{|l|l|l}
\hline 1. AGENCY USE ONLY (Leave blank) & $\begin{array}{r}\text { 2. REPORT DATE } \\
\text { September } 2002\end{array}$ & $\begin{array}{r}\text { 3. REPORT TYPE AND DATES COVERED } \\
\text { Technical Memorandum }\end{array}$
\end{tabular}

\section{TITLE AND SUBTITLE}

Flutter Analysis of a Transonic Fan 5. FUNDING NUMBERS

6. AUTHOR(S)

WU-781-30-11-00

R. Srivastava, M.A. Bakhle, T.G. Keith, Jr., and G.L. Stefko

\section{PERFORMING ORGANIZATION NAME(S) AND ADDRESS(ES)}

National Aeronautics and Space Administration

John H. Glenn Research Center at Lewis Field

Cleveland, Ohio 44135-3191

\section{SPONSORING/MONITORING AGENCY NAME(S) AND ADDRESS(ES)}

National Aeronautics and Space Administration

Washington, DC 20546-0001
8. PERFORMING ORGANIZATION REPORT NUMBER

E-13511

10. SPONSORING/MONITORING AGENCY REPORT NUMBER

NASA TM-2002-211818

11. SUPPLEMENTARY NOTES

Prepared for the Turbo Expo 2002 cosponsored by the American Society of Mechanical Engineers and the International Gas Turbine Institute, Amsterdam, The Netherlands, June 3-6, 2002. Portions of this material were presented at the meeting. R. Srivastava, M.A. Bakhle, and T.G. Keith, Jr., University of Toledo, Toledo, Ohio; and G.L. Stefko, NASA Glenn Research Center. R. Srivastava and M.A. Bakhle, NASA Resident Research Associates at Glenn Research Center. Responsible person, R. Srivastava, organization code 5930, 216-433-6045.

12a. DISTRIBUTION/AVAILABILITY STATEMENT

Unclassified - Unlimited

Subject Category: 07

Distribution: Nonstandard

Available electronically at http://gltrs.grc.nasa.gov

This publication is available from the NASA Center for AeroSpace Information, 301-621-0390.

13. ABSTRACT (Maximum 200 words)

This paper describes the calculation of flutter stability characteristics for a transonic forward swept fan configuration using a viscous aeroelastic analysis program. Unsteady Navier-Stokes equations are solved on a dynamically deforming, body fitted, grid to obtain the aeroelastic characteristics using the energy exchange method. The non-zero inter-blade phase angle is modeled using phase-lagged boundary conditions. Results obtained show good correlation with measurements. It is found that the location of shock and variation of shock strength strongly influenced stability. Also, outboard stations primarily contributed to stability characteristics. Results demonstrate that changes in blade shape impact the calculated aerodynamic damping, indicating importance of using accurate blade operating shape under centrifugal and steady aerodynamic loading for flutter prediction. It was found that the calculated aerodynamic damping was relatively insensitive to variation in natural frequency.

\section{SUBJECT TERMS}

Aeroelasticity; Turbomachine; Fan; Viscous; Numerical

17. SECURITY CLASSIFICATION OF REPORT

Unclassified
18. SECURITY CLASSIFICATION OF THIS PAGE

Unclassified
19. SECURITY CLASSIFICATION OF ABSTRACT

Unclassified

NSN 7540-01-280-5500

15. NUMBER OF PAGES

14

16. PRICE CODE

20. LIMITATION OF ABSTRACT 